\title{
Review Article \\ Prevalence of HIV and Syphilis Infection among Men Who Have Sex with Men in China: A Meta-Analysis
}

\author{
Yunhua Zhou, ${ }^{1}$ Dongliang Li, ${ }^{2}$ Dabing Lu, ${ }^{1}$ Yuhua Ruan, ${ }^{3}$ Xiao Qi, ${ }^{2}$ and Ge Gao ${ }^{1}$ \\ ${ }^{1}$ Department of Epidemiology and Health Statistics, School of Public Health, Suzhou University, Suzhou, Jiangsu 215123, China \\ ${ }^{2}$ Chaoyang Center for Disease Control and Prevention, Beijing 100021, China \\ ${ }^{3}$ State Key Laboratory for Infectious Disease Prevention and Control, National Center for AIDS/STD Control and Prevention, Chinese \\ Center for Disease Control and Prevention, Collaborative Innovation Center for Diagnosis and Treatment of Infectious Disease, \\ Beijing 100026, China \\ Correspondence should be addressed to Ge Gao; gaoge01@163.com
}

Received 28 September 2013; Accepted 6 January 2014; Published 23 April 2014

Academic Editor: Muktar Aliyu

Copyright (C) 2014 Yunhua Zhou et al. This is an open access article distributed under the Creative Commons Attribution License, which permits unrestricted use, distribution, and reproduction in any medium, provided the original work is properly cited.

\begin{abstract}
Objectives. To figure out the most current prevalence of HIV and syphilis in MSM in China. Methods. A meta-analysis was conducted on the studies searched through PubMed, CNKI, and Wanfang published between 1 January 2009 and 11 April 2013. Results. Eightyfour eligible studies, either in Chinese or in English, were included in this review. The pooled prevalence of HIV and syphilis infection in MSM in China was 6.5\% and 11.2\%, respectively. The subgroup analyses indicated that the prevalence of HIV infection was higher in the economically less developed cities than that in the developed cities $(7.5 \%$ versus $6.1 \%, P<0.05)$. In contrast, the prevalence of syphilis infection was lower in less developed cities than in developed cities ( $8.6 \%$ versus $15.1 \%)$. Studies with a sample size smaller than 500 had a lower prevalence of HIV and syphilis infection than those with a sample size greater than $500(5.9 \%$ versus $7.2 \%$ for HIV; $11.0 \%$ versus $11.5 \%$ for syphilis, respectively). Conclusions. HIV and syphilis infection are prevalent in MSM in China. The different prevalence of HIV and syphilis infection between developing and developed cities underscores the need to target prevention strategies based on economic conditions.
\end{abstract}

\section{Introduction}

The human immunodeficiency virus (HIV) and syphilis infection epidemics present an intractable problem to the world. This is also true in China, where there is a marked increase of people living with HIV/AIDS, from 740,000 in 2009 to 780,000 in 2011. Approximately $17.4 \%$ of new HIV cases are attributed to homosexual transmission [1]. It was said that the epidemic of HIV infection among men who have sex with men (MSM) has been the gravest of the six newborn HIV/AIDS challenges in China [2]. From 2009 to 2013, the prevalence of HIV among MSM ranged from $1.7 \%$ to $21.0 \%$ in China [3, 4]. A recent meta-analysis reported that almost 5.3\% (95\% CI: $4.8 \%-5.8 \%$ ) of MSM in China were living with HIV, which was more than 90 times higher than the general public [5]. The prevalence of syphilis in MSM increased from $6.9 \%$ to $11.8 \%$ between 2003 and $2009[6,7]$.
The fast growth of the HIV epidemic has been observed in some reports $[5,8]$. Although there have been several metaanalyses on prevalence of HIV and syphilis in MSM $[5,8,9]$, the most recent meta-analysis only included studies until 2008. Thus, it is important for us to have a better and more thorough understanding of the current prevalence of HIV and syphilis. Therefore, we performed a meta-analysis of all available literature published from 2009 to 2013.

Given the poor awareness of AIDS-related knowledge in economically developing cities, which may lead to higher prevalence of marriage and bisexuality and lower condom use than economically developed cities, we also carried out a subgroup analysis to explore the differences in HIV and syphilis prevalence between developing and developed cities in China. Results from the analyses may guide future policies for more rational allocation of prevention and treatment resources. 


\section{Methods}

2.1. Search Strategy. A systematic review of published articles was conducted by searching the following database: PubMed, Chinese National Knowledge Infrastructure (CNKI), and Wanfang from January 1, 2009, to April 11, 2013. Search terms included HIV, AIDS, syphilis, STD, sexually transmitted disease, prevalence, MSM, homosexual, gay, sex between men, and China. Reference lists were also referred to for additional articles. This review was conducted according to the Preferred Reporting Items for Systematic Review and Meta-Analyses (PRISMA) statement issued in 2009.

2.2. Study Selection. Studies were included if they met the following criteria: (1) published in Chinese or English language; (2) cross-sectional or cohort studies that reported either HIV or syphilis prevalence or both; (3) HIV and syphilis infection was diagnosed from at least two laboratory serologic testing methods; (4) articles that presented study design information, including study period, study site, and sampling method. Studies were excluded if (1) the study participants were MB (Money Boys) or young MSM (younger than 18 years old); (2) the sample size was smaller than 150. Studies with no specific study cities were also excluded from subgroup analyses. If articles with the same data were published in both Chinese and English, the English source was included.

2.3. Data Extraction. The first author extracted the following data from the included studies, which was later verified by the second author: the first author and published year, study period, study site, sampling methods, average age of MSM participants, sample size, and prevalence of HIV infection or syphilis infection or both. The study sites were divided into developing and developed cities (as assessed on the basis of based on per capita gross domestic product (GDP) for each city). Developing cities were defined as those with a per capita GDP lower than 15,000 RMB and developed cities were defined as cities with per capita GDP higher than 15,000 RMB. GDP of each city per personyear was obtained from http://tieba.baidu.com/p/2312163828. Disagreements were resolved by discussion. If no consensus could be reached, a third author would be referred to.

2.4. Validity Assessment. Validity assessments were accomplished by two workers. Studies were considered to be of high validity if they met the following criteria: (1) reported both HIV and syphilis infection; (2) used two or more recruitment methods; (3) sample size larger than 500; (4) published in English.

2.5. Statistical Analysis. Meta-analyses of the prevalence of HIV and syphilis infection among MSM were carried out by Meta-Analyst software (Beta 3.13). Q-test (significance level $P<0.10$ ) and $I^{2}$ (significance level $I^{2}>0.25$ ) statistics were calculated to measure homogeneity of studies. Studies that had either $Q\left\langle 0.10\right.$ or $\left.I^{2}\right\rangle 0.25$ were defined as heterogeneous. Potential publication bias was assessed by
Begg's test. Pooled prevalence of HIV and syphilis infection, 95\% confidence intervals, and the relative weight for each study were calculated by using random effects models. Due to the heterogeneity which is commonly observed in meta-analysis concerning sensitive groups such as MSM, we conducted a meta-regression with 10,000 permutations in a Monte Carlo simulation to explore the sources of betweenstudy heterogeneity with the following covariates: economy status, sampling methods, sample size, and published year. Subgroup analyses were conducted to obtain the prevalences of HIV and syphilis from different stratifications.

\section{Results}

3.1. Study Selection for Meta-Analyses. 1222 articles were retrieved after the initial search from databases and another 6 articles were included from reference lists. A total of 1096 articles were removed after screening of titles and abstracts because they were not topically relevant $(N=1077)$, were reviews $(N=7)$, and used the same data $(N=12)$. 151 articles were eligible for full-text screening and 67 were further excluded because they did not report the sampling methods or study site $(N=19)$, did not mention the study period $(N=5)$, had a sample size smaller than $150(N=4)$, included MB or young MSM $(N=6)$, presented neither HIV nor syphilis prevalence $(N=12)$, just used one method to diagnosis syphilis $(N=20)$, and tested HIV infection by urine $(N=1)$. The detailed process of data selection is illustrated by Figure 1.

3.2. Study Characteristic. Eighty-four studies with estimates of HIV prevalence (English 18, Chinese 66) and seventysix studies with estimates of syphilis prevalence (English 17, Chinese 59) were finally identified in this review, which covers 59 cities from 29 provinces and municipalities in China (no studies from Hainan, Tibet, Hong Kong, Macao, and Taiwan). The prevalence of HIV and syphilis ranged from $1.7 \%$ to $21.0 \%$ and $0.9 \%$ to $31.2 \%$, respectively $[3,4,10-$ 89]. In the meta-analysis of pooled prevalence of HIV, the sample size ranged from 150 to 6101 (total 71,845), and in the estimating of syphilis prevalence, the sample size oscillated between 157 and 6101 (total 65,162). About half of them were located in developing cities $(50.7 \%$ and $51.4 \%$ in analyses of $\mathrm{HIV}$ and syphilis prevalence, resp.,). The following sampling methods were used to recruit participants: snow ball $(N=$ $27)$, respondent driven sampling (RDS) $(N=15)$, multiple sampling methods $(n=23)$, and others $(N=19)$. The basic information of the 84 included studies is represented in Table 1.

3.3. Pooled Prevalence of HIV and Syphilis. According to our meta-analyses, the estimates of HIV prevalence in MSM in China ranged from $1.7 \%$ to $21.0 \%$. The pooled prevalence of HIV infection was $6.5 \%$ (95\% CI $5.6 \%$ to $7.4 \%$ ), as seen in Figure 2, with substantial heterogeneity $\left(P<0.001, I^{2}=\right.$ $0.490)$. Estimates of syphilis prevalence ranged from $0.9 \%$ to $31.2 \%$ and the overall prevalence was $11.2 \%$ (95\% CI $10.0 \%$ to 


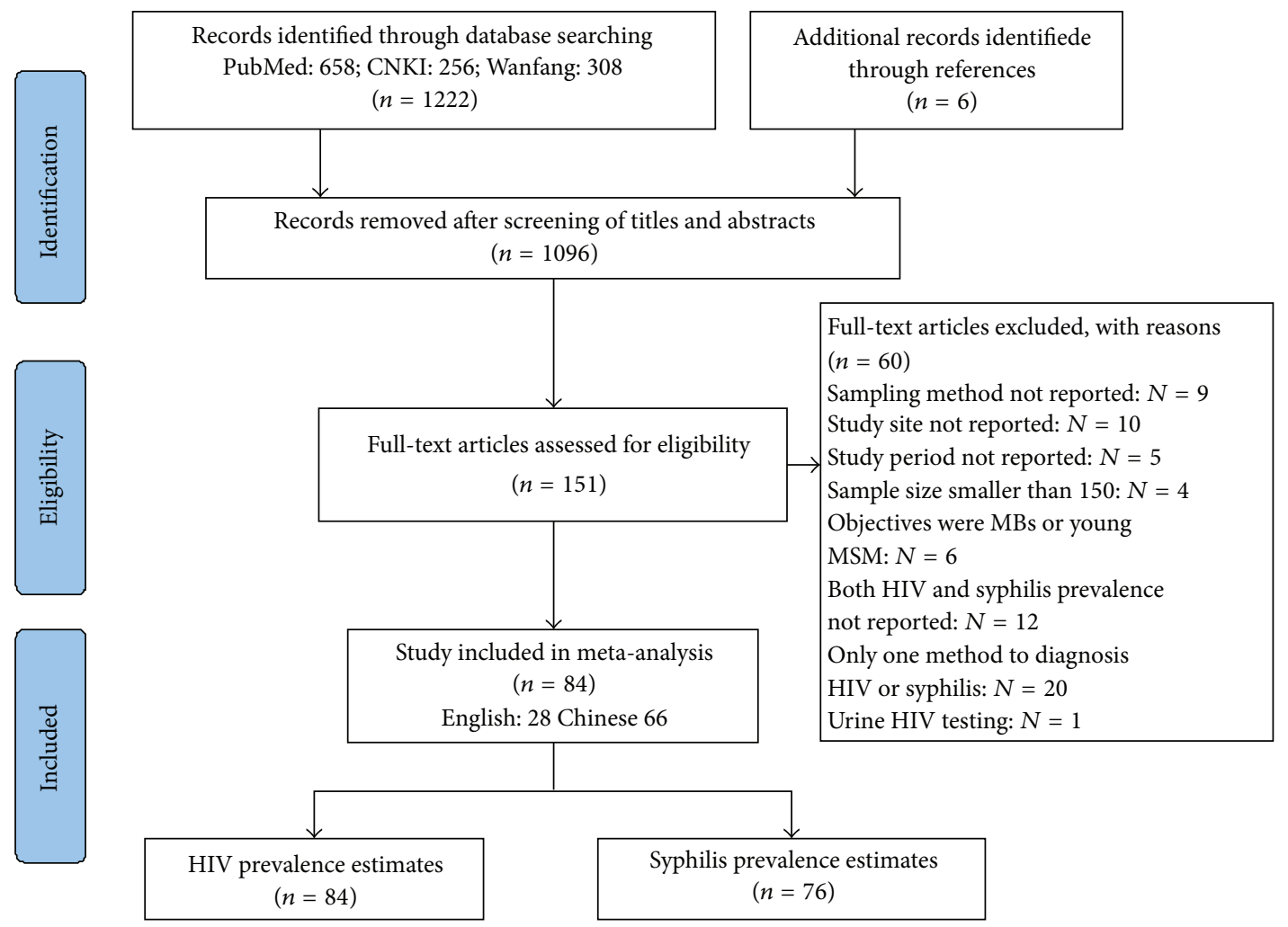

FIGURE 1: Flow chart of the meta-analysis studies selection.

TABLE 1: Meta-regression and subgroup analyses of HIV and syphilis prevalence among men who have sex with men in China.

\begin{tabular}{|c|c|c|c|c|}
\hline \multirow{3}{*}{ Study characteristic } & \multicolumn{4}{|c|}{ Stratified meta-analysis } \\
\hline & \multicolumn{2}{|r|}{ HIV } & \multicolumn{2}{|c|}{ Syphilis } \\
\hline & Prevalence (95\% CI) & Meta-regression ( $\beta, P$ value $)$ & Prevalence (95\% CI) & Meta-regression ( $\beta, P$ value) \\
\hline \multicolumn{5}{|l|}{ Sample size } \\
\hline$<500$ & $5.9 \%(5.0-7.0 \%)$ & 1.017 & $11.0 \%(9.3-12.9 \%)$ & 1.007 \\
\hline$>500$ & $7.2 \%(5.8-8.9 \%)$ & $P=0.056$ & $11.5 \%(9.8-13.5 \%)$ & $P=0.670$ \\
\hline \multicolumn{5}{|l|}{ Sampling methods } \\
\hline RDS & $7.4 \%(5.7-9.7 \%)$ & 0.996 & $9.1 \%(7.1-11.6 \%)$ & 1.009 \\
\hline Snow ball & $7.2 \%(5.4-9.4 \%)$ & $P=0.356$ & $13.3 \%(10.8-16.2 \%)$ & $P=0.198$ \\
\hline Multiple Methods & $5.9 \%(4.5-7.7 \%)$ & & $10.5 \%(8.2-13.3 \%)$ & \\
\hline Others & $6.2 \%(5.6-7.4 \%)$ & & $12.2 \%(10.0-14.9 \%)$ & \\
\hline \multicolumn{5}{|l|}{ Economy status } \\
\hline$<15,000 \$$ & $7.5 \%(6.5-8.6 \%)$ & 0.971 & $8.8 \%(7.7-10.0 \%)$ & 1.074 \\
\hline$>15,000 \$$ & $6.1 \%(4.7-8.0 \%)$ & $P=0.002$ & $15.5 \%(13.0-18.3 \%)$ & $P=0.000$ \\
\hline \multicolumn{5}{|l|}{ Published year } \\
\hline $2009-2010$ & $5.9 \%(5.1-6.9 \%)$ & 1.017 & $12.1 \%(10.6-13.7 \%)$ & -0.980 \\
\hline 2011-2013 & $7.6 \%(6.1-9.5 \%)$ & $P=0.063$ & $9.6 \%(7.6-12.1 \%)$ & $P=0.217$ \\
\hline
\end{tabular}

32.6\%), as shown in Figure 3, with substantial heterogeneity observed $\left(P<0.001, I^{2}=0.489\right)$.

3.4. Meta-Regression and Subgroup Analyses. Results of metaregression indicated that economic status and sample size contributed to the heterogeneity between studies (Table 2).
Four and two studies were further excluded because of the absence of specific study cities in the subgroup analyses of HIV and syphilis prevalence by different economic status, respectively. The prevalence of HIV infection was slightly higher in developing cities (7.5\%) than in developed cities $(6.1 \%)$, whereas the prevalence of syphilis was significantly lower in developing cities (8.6\%) than in developed cities 


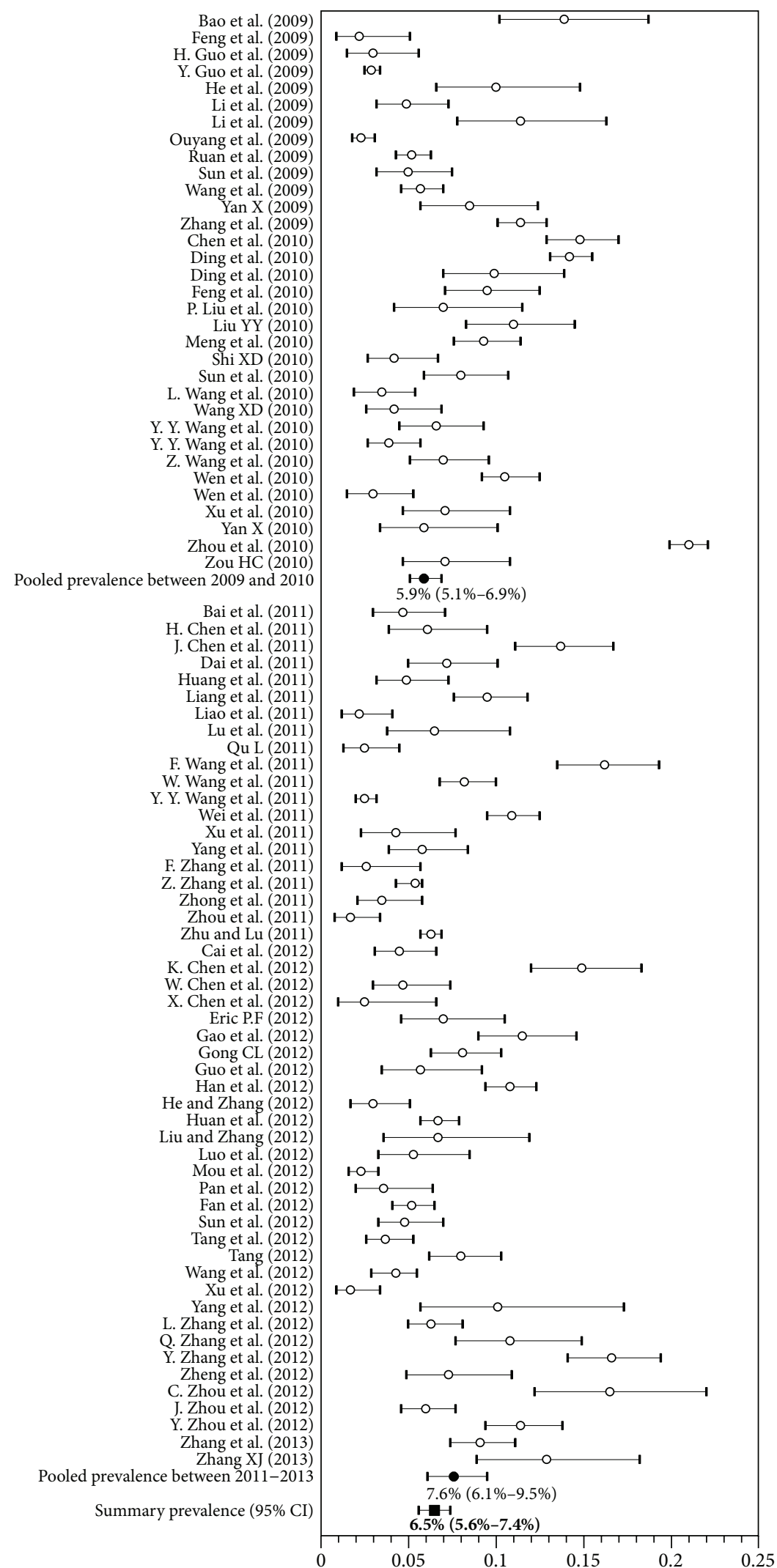

FIgURE 2: Forest plot showing the meta-analyses of pooled prevalence of HIV among men who have sex with men in China. 


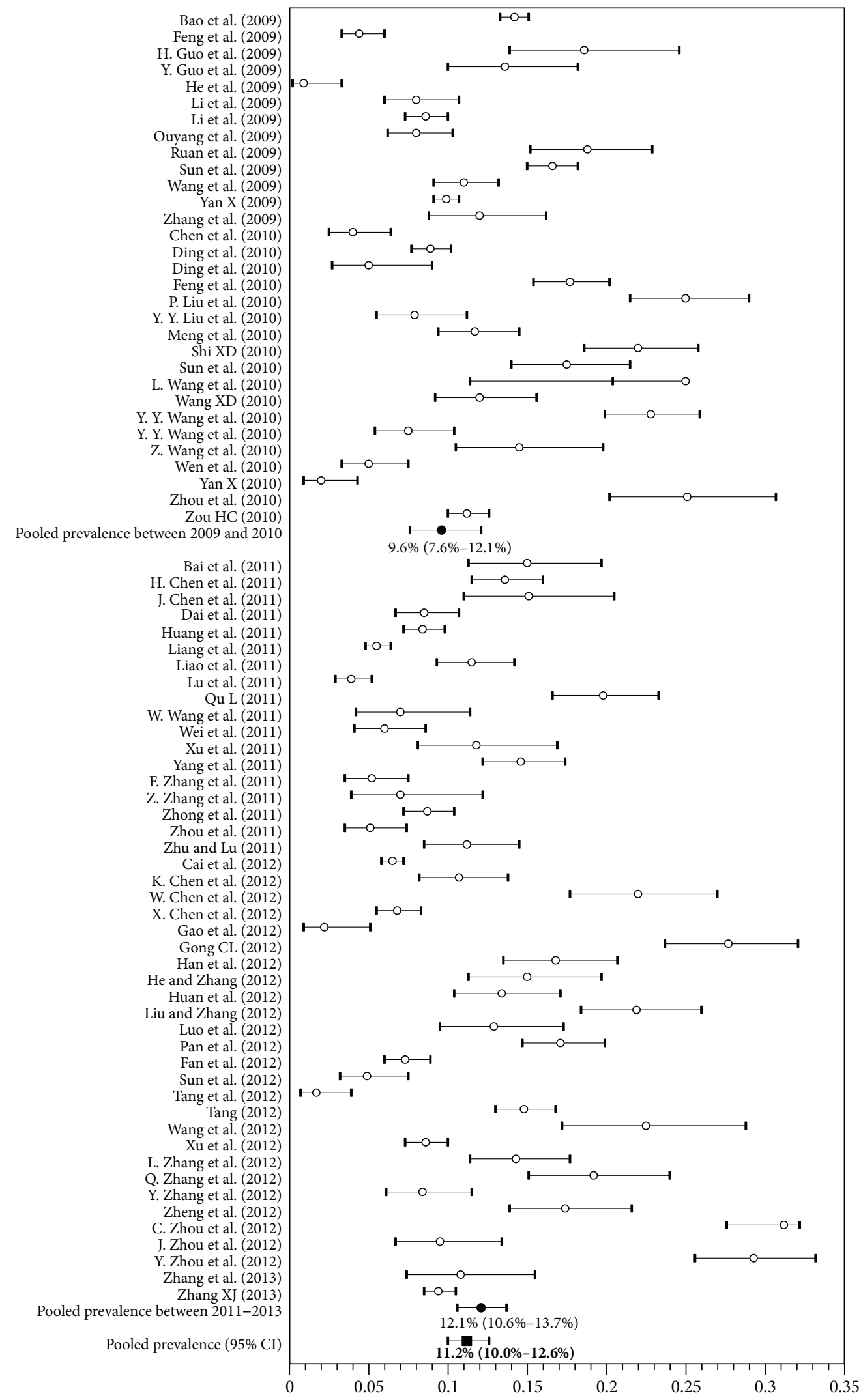

FIGURE 3: Forest plot showing the meta-analyses of the pooled prevalence of syphilis among men who have sex with men in China. 
TABLE 2: Basic information of the 84 included studies.

\begin{tabular}{|c|c|c|c|c|c|c|}
\hline \multirow{2}{*}{ First author, published year } & \multirow{2}{*}{ Sample size } & \multirow{2}{*}{ Sampling methods } & \multirow{2}{*}{ Location } & \multirow{2}{*}{ Economy status } & \multicolumn{2}{|c|}{ Prevalence (\%) } \\
\hline & & & & & HIV & Syphilis \\
\hline Liang, 2011 [35] & 511 & Multiple methods & Foshan & Developed & 7.0 & 8.0 \\
\hline Sun, 2009 [50] & 401 & Multiple methods & Dalian & Developed & 4.2 & 17.5 \\
\hline Yang, 2012 [72] & 264 & VCT & Fuyang & Developing & 5.7 & \\
\hline Chen, 2012 [15] & 400 & Snow ball & Guilin & Developing & 3.5 & 4.0 \\
\hline Wen, 2010 [64] & 452 & Snow ball & Guangzhou & Developed & 4.9 & 6.0 \\
\hline Huang, 2011 [32] & 395 & Snow ball & Hefei & Developing & 3.0 & 13.4 \\
\hline Wang, 2009 [54] & 1348 & Multiple Methods & Heilongjiang & Developing & 2.3 & 14.8 \\
\hline Wang, 2010 [61] & 200 & Snow ball & Lanzhou & Developing & 7.0 & 12.5 \\
\hline Wang, 2012 [58] & 400 & RDS & Mianyang & Developing & 11.0 & 23.5 \\
\hline $\mathrm{Lu}, 2011[40]$ & 354 & RDS & Nanchang & Developing & 4.2 & 7.9 \\
\hline Chen, 2010 [3] & 469 & Snow ball & Nanning & Developing & 1.7 & 10.7 \\
\hline Bao, 2009 [11] & 6101 & RDS & 14 cities & Classified $^{\mathrm{a}}$ & 6.3 & 14.0 \\
\hline Chen, 2012 [16] & 300 & Snow ball & Yangzhou & Developed & 7.3 & 22.0 \\
\hline Li, 2009 [34] & 1773 & Multiple methods & Chongqing & Developing & 10.6 & 8.4 \\
\hline Guo, 2009 [27] & 204 & Venues-based & Tianjin & Developed & 5.9 & 18.7 \\
\hline Liu, 2012 [90] & 507 & Snow ball & Changsha & Developed & 4.3 & 25.1 \\
\hline $\mathrm{Qu}, 2011[91]$ & 805 & Snow ball & 2 cities & Developed & 3.7 & 14.1 \\
\hline Chen, 2011 [12] & 831 & VCT & Kunming & Developing & 11.4 & 13.6 \\
\hline Zhou, 2011 [83] & 1166 & Snow ball & Chongqing & Developing & 14.8 & 8.7 \\
\hline Han, 2012 [92] & 272 & Venues-based & Taiyuan & Developing & 8.5 & 13.6 \\
\hline Tang, 2011 [93] & 408 & Venues-based & Guilin & Developing & 2.5 & 4.9 \\
\hline $\mathrm{Xu}, 2011$ [69] & 436 & Venues-based & Liaoning & Dropped out ${ }^{\mathrm{b}}$ & 3.0 & 5.0 \\
\hline Bai et al., 2011 [94] & 280 & Snow ball & Suzhou & Developed & 7.1 & 15.0 \\
\hline Zhou, 2011 [95] & 491 & RDS & Chongqing & Developing & 14.9 & 5.1 \\
\hline Fan, 2012 [47] & 500 & RDS & Beijing & Developed & 8.0 & 22.0 \\
\hline Liao et al., 2011 [96] & 2996 & Multiple methods & Shandong & Developed & 2.5 & 5.5 \\
\hline Feng et al., 2009 [97] & 2044 & Venues-based & Chongqing & Developing & 11.5 & 8.9 \\
\hline He, 2009 [29] & 423 & RDS & Guangzhou & Developed & 1.3 & 14.8 \\
\hline Eric, 2011 [98] & 288 & Snow ball & Yuxi & Developing & 10.8 & \\
\hline Zheng, 2012 [81] & 157 & Multiple methods & Beijing & Developed & 2.5 & 7.0 \\
\hline Wei, $2011[63]$ & 220 & Snow ball & Taizhou & Developing & 13.4 & 14.5 \\
\hline Zhong et al., 2011 [99] & 379 & RDS & Guangzhou & Developed & 5.2 & 17.5 \\
\hline Zhang, 2012 [74] & 503 & RDS & Chongqing & Developing & 15.7 & 6.6 \\
\hline Xiao, $2009[66]$ & 1692 & Multiple methods & Chongqing & Developing & 10.8 & 8.6 \\
\hline Xiao, 2010 [67] & 4983 & Multiple methods & 20 cities & Dropped out ${ }^{\mathrm{b}}$ & 2.9 & 9.8 \\
\hline Zhang et al., 2011 [100] & 302 & Snow ball & Beijing & Developed & 9.9 & 19.2 \\
\hline Zhang et al., 2012 [101] & 3314 & Snow ball & Chongqing & Developing & 14.2 & 9.4 \\
\hline Zhang, 2013 [75] & 463 & Snow ball & Harbin & Developing & 9.5 & 14.3 \\
\hline Guo et al., 2009 [102] & 433 & Venues-based & 2 cities & Developed & 5.8 & 27.7 \\
\hline Ruan et al., 2009 [103] & 541 & Multiple methods & Beijing & Developed & 4.8 & 19.8 \\
\hline Zou et al., 2010 [104] & 429 & Internet & 2 cities & Classified $^{\mathrm{a}}$ & 4.8 & 11.4 \\
\hline Wang, 2011 [105] & 2020 & Surveillance & 4 cities & Developing & 2.3 & \\
\hline Gao, 2012 [106] & 962 & Multiple methods & Beijing & Developed & 6.3 & 17.7 \\
\hline Zhou et al., 2010 [107] & 550 & Multiple methods & Beijing & Developed & 4.5 & \\
\hline Zhou, 2012 [108] & 294 & VCT & Shanghai & Developed & 6.1 & 9.5 \\
\hline
\end{tabular}


TABLE 2: Continued.

\begin{tabular}{|c|c|c|c|c|c|c|}
\hline \multirow{2}{*}{ First author, published year } & \multirow{2}{*}{ Sample size } & \multirow{2}{*}{ Sampling methods } & \multirow{2}{*}{ Location } & \multirow{2}{*}{ Economy status } & \multicolumn{2}{|c|}{ Prevalence (\%) } \\
\hline & & & & & HIV & Syphilis \\
\hline Ouyang, 2009 [44] & 617 & RDS & Chongqing & Developing & 16.8 & 10.9 \\
\hline Meng, 2010 [42] & 287 & Multiple methods & Changde & Developing & 3.5 & 12.9 \\
\hline Tang, $2012[52]$ & 303 & Multiple methods & Dazhou & Developing & 3.6 & 1.7 \\
\hline Sun, 2012 [49] & 2006 & Multiple methods & Dalian & Developed & 5.2 & 16.6 \\
\hline Dai, 2011 [109] & 1315 & VCT & Guangzhou & Developed & 5.4 & 6.8 \\
\hline Mou, 2012 [110] & 1526 & Venues-based & Guangzhou & Developed & 5.7 & \\
\hline Wen, $2010[64]$ & 452 & Snow ball & Guangzhou & Developed & 4.9 & 6.0 \\
\hline Wang, 2011 [111] & 300 & RDS & Kunshan & Developed & 5.3 & 25.0 \\
\hline Sun, 2010 [112] & 1350 & RDS & 2 cities & Developing & 5.2 & 7.3 \\
\hline Zhu, $2011[88]$ & 259 & Surveillance & Wuxi & Developed & 13.9 & 25.1 \\
\hline Zhang, 2009 [76] & 231 & RDS & Urumqi & Developing & 2.2 & 10.8 \\
\hline Chen, 2011 [113] & 889 & Snow ball & Lanzhou & Developing & 6.0 & 13.6 \\
\hline Hong et al., 2009 [114] & 593 & Venues-based & Changzhou & Developed & 13.7 & 31.2 \\
\hline Liu, 2012 [37] & 661 & Snow ball & Nanjing & Developed & 3.9 & 11.5 \\
\hline He, 2012 [115] & 235 & Multiple methods & Geermu & Developing & 4.3 & 0.9 \\
\hline Gong, 2010 [24] & 252 & Snow ball & Quanzhou & Developing & 2.6 & 2.2 \\
\hline Zhang, 2012 [77] & 300 & RDS & Shenzhen & Developed & 7.0 & 12.0 \\
\hline Pan, 2012 [45] & 675 & Multiple methods & Shenzhen & Developed & 8.0 & 41.2 \\
\hline Shi, 2010 [116] & 906 & Venues-based & Shenzhen & Developed & 4.2 & 14.5 \\
\hline Cai, 2012 [117] & 5232 & VCT & Shenzhen & Developed & 6.5 & 21.0 \\
\hline Wang, 2010 [55] & 900 & RDS & Shenyang & Developed & 9.3 & 11.0 \\
\hline Wang, 2011 [118] & 450 & Venues-based & Shijiazhuan & Developing & 2.2 & 7.6 \\
\hline Wang, 2010 [61] & 150 & Snow ball & Shijiazhuan & Developing & 6.7 & 11.3 \\
\hline Bai et al., 2011 [119] & 280 & Multiple methods & Suzhou & Developed & 7.3 & 22.0 \\
\hline Zhang et al., 2011 [73] & 717 & Multiple methods & Suzhou & Developed & 8.1 & 14.6 \\
\hline Xu et al., 2012 [70] & 211 & Multiple methods & Taizhou & Developing & 10.0 & 11.8 \\
\hline Wang et al., 2011 [57] & 201 & Snow ball & Urumqi & Developing & 6.5 & 7.0 \\
\hline Liu et al., 2010 [38] & 456 & RDS & Wuhan & Developed & 6.6 & 21.9 \\
\hline Zhang et al., 2011 [80] & 404 & Snow ball & Xining & Developing & 7.2 & 8.4 \\
\hline Wang et al., 2010 [62] & 750 & Multiple methods & Yangzhou & Developed & 9.3 & 22.8 \\
\hline Chen et al., 2012 [14] & 218 & Snow ball & Chongqing & Developing & 16.5 & 15.1 \\
\hline Yang et al., 2011 [71] & 305 & Multiple methods & Dali & Developing & 3.0 & 2.0 \\
\hline Luo et al., 2012 [41] & 1237 & Snow ball & 13 cities & Developing & 8.2 & 3.9 \\
\hline $\mathrm{Xu}, 2010[68]$ & 1864 & Multiple methods & 4 cities & Classified $^{\mathrm{a}}$ & 6.7 & \\
\hline Ding et al., 2010 [19] & 743 & Snow ball & Chongqing & Developing & 16.6 & 8.5 \\
\hline Ding et al., 2010 [20] & 202 & Snow ball & Chongqing & Developing & 12.9 & 5.0 \\
\hline Li, 2009 [34] & 1691 & Multiple methods & Chongqing & Developing & 10.9 & 8.6 \\
\hline Feng, 2010 [22] & 946 & Snow ball & Chongqing & Developing & 15.8 & \\
\hline Guo et al., 2012 [25] & 109 & Surveillance & Zunyi & Developing & 10.1 & 1.0 \\
\hline
\end{tabular}

${ }^{a}$ Study sites were classified into different economy status when subgroup analysis was conducted; ${ }^{b}$ Study was dropped out then subgroup analysis was conducted.

(15.1\%). Studies with a sample size smaller than 500 had a lower prevalence of HIV and syphilis infection than those with a sample size greater than $500(5.9 \%$ versus $7.2 \%, 11.0 \%$ versus $11.5 \%$, resp.) (Table 2 ).

Although the published year and sampling methods did not contribute to between-study variance, we also conducted subgroup analyses based on them. Although we only divided the published year into two groups, an uptrend of HIV infection and a decrease in syphilis infection were still observed (Table 2).

\section{Discussion}

This is an updated meta-analysis that presents the most current prevalence of HIV and syphilis infection in MSM in China. In order to obtain the prevalence from developing 
and developed cities, we also carried out a subgroup analysis by different economic status according to meta-regression. To our knowledge, this is the first study to compare the prevalence of HIV and syphilis infection between developing and developed cities in China. A national study survey of 61 cities by $\mathrm{Wu}$ reported the prevalence of HIV in MSM from the southwest, east, south, and northeast of China but did not account for the different economic conditions of each city [6].

Overall, eighty-four articles published between January 1 , 2009, and April 11, 2013 were included in this review. It was observed that the prevalence of HIV and syphilis infection among MSM in China was 6.5\% (95\% CI 5.6\% to 7.4\%) and $11.2 \%$ (95\% CI $10.0 \%$ to $12.6 \%$ ), respectively, which was lower compared to other countries and cities. For instance, the prevalence of HIV among MSM was $14.2 \%$ in Brazil, $10.6 \%$ in Kenya, 21.5\% in Senegal, 9.0\% in Indonesia, 14.7\% in India, and $24.6 \%$ in Thailand [120-123].

In spite of the relatively lower prevalence, there was evidence for the uptrend of HIV and syphilis infection among MSM in China. A meta-analysis of Chow reported that HIV infection among MSM has increased over the past years, from $1.4 \%$ (95\% CI $0.8 \%-2.4 \%$ ) during 2001-2003, to $2.3 \%$ (95\% CI 2.0\%-2.6\%) during 2004-2006, and to 5.3\% (95\% CI 4.8\%-5.8\%) during 2007-2009 [8]. Results from our study indicate that the prevalence of HIV among MSM is still increasing. The expanding epidemic may be associated with the special role of MSM in China. Homosexuality is still not widely accepted by the general population. Therefore, marriage between MSM and women remains common, nn which case MSM might act as a bridge for HIV transmission to other MSM and the general population. It was reported that the prevalence of bisexual behavior among MSM in China was as high as $31.2 \%$ [124].

The subgroup analyses showed that the prevalence of HIV infection was 7.5\% from developing cities and $6.1 \%$ from developed cities, whereas the prevalence of syphilis was $8.6 \%$ from developing cities and $15.1 \%$ from developed cities. The exact reasons for this finding are unclear, but one possible reason is that syphilis is a curable disease and several large scale public health programs were conducted in several developing cities in the past few years [74].

Several limitations of our analyses must be kept in mind. First, substantial heterogeneity was observed in our analysis. We found that study site, sample size, and sampling methods contributed to the heterogeneities. These factors may also have contributed to the increasing trend of HIV and syphilis infection in MSM in China. A meta-analysis of Chow reported that articles published in English were more likely to present high prevalence than Chinese articles, which may have resulted in between-study variance. The presence of publication bias was also a considerable limitation in our analysis (Figure 4). With the strict inclusion criteria, we excluded studies with a sample size smaller than 150 and those with only one testing method to diagnose syphilis. There are also a large number of unpublished articles (e.g., government documents) and studies that reported relatively low prevalence. Third, there were few studies from rural areas, which may have led to an overestimation of HIV and syphilis

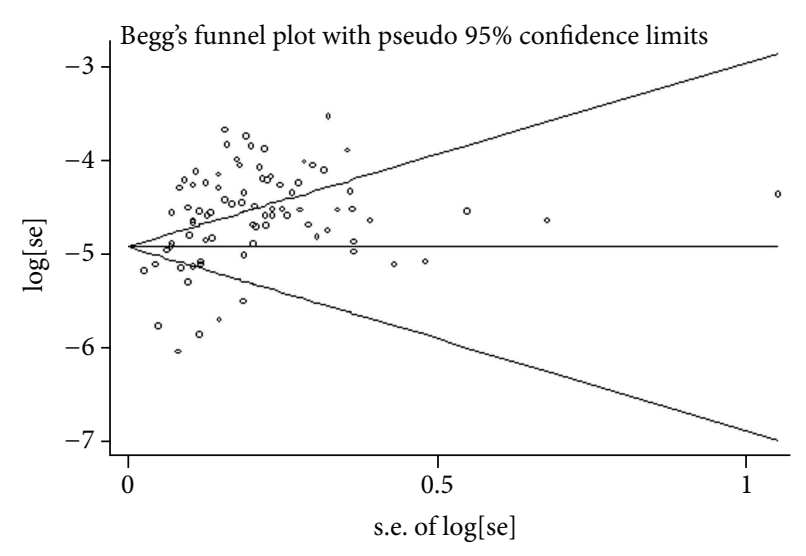

FIGURE 4: Begg's funnel plot showing the potential publication bias.

prevalence. More studies of rural MSM studies are needed in the future. Fourth, several studies that did not specify the city location were excluded from the subgroup analysis, which may have increased the possibility of publication bias. Fifth, the economic classification of the cities was only based on the per capita GDP; results may only partially reflect the true economic status of the city.

Despite the limitations listed above, our meta-analyses employed a strict inclusion criteria and valid search strategy in order to provide an objective, authentic, and current estimate of HIV and syphilis prevalence among MSM in China, with a large aggregate sample size of 75036 . We also conducted a subgroup analysis to present the different prevalence rates of HIV and syphilis infection in developing and developed cities.

In conclusion, HIV and syphilis are prevalent among MSM in China; HIV prevalence is higher in developing cities than in developed cities, while the situation of syphilis is just the opposite. These results urgently indicate the need for strategies aimed at prevention, surveillance, and treatment. Moreover, corresponding policies should be drawn up by the local government on the basis of local economic status.

\section{Conflict of Interests}

There are no conflict of interests.

\section{Acknowledgments}

This work was supported by the National Nature Science Foundation of China no. 81273188 and the National Mega Projects on Key Infectious Disease Control of China Ministry of Science and Technology no. 2012ZX10004-904. The autors thank Zongda Jin, Wei Li, and Guochong Chen for their assistance with the literature search and Stephen Pan for the English editing. The authors are also grateful to Jiachen Shi and Yin Fu for data extracting and checking and all the authors of the original studies included in our analysis. 


\section{References}

[1] Chinese Ministry of Health, Reports on the Epidemic of AIDS in 2011, Chinese Ministry of Health, Beijing, China, 2011.

[2] Z. Y. Wu and Y. Wang, "Introduction: China meets new AIDS challenges," Journal of Acquired Immune Deficiency Syndromes, vol. 53, supplement 1, pp. S1-S3, 2012.

[3] S. H. Chen, N. H. Yang, and J. Zhou, "Survey on the MSM group of knowledge and related HIV/AIDS characteristic and STD/HIV infection in Nanning," Modern Preventive Medicine, vol. 37, pp. 3928-3932, 2010.

[4] Y. Cai, Y. Song, P. Pan et al., "Distribution characteristics and influencing factors of syphilis among men who have sex with men in Shenzhen," Chinese Journal Of Disease Control \& Prevention, vol. 16, no. 12, pp. 1106-1108, 2012.

[5] E. P. Chow, D. P. Wilson, J. Zhang, J. Jing, and L. Zhang, "Human immunodeficiency virus prevalence is increasing among men who have sex with men in China: findings from a review and meta-analysis," Sexually Transmitted Diseases, vol. 38, no. 9, pp. 845-857, 2011.

[6] Z. Wu, J. Xu, E. Liu et al., "HIV and syphilis prevalence among men who have sex with men: a cross-sectional survey of 61 cities in China," Clinical Infectious Diseases, vol. 57, no. 2, pp. 298-309, 2013.

[7] J. Jiang, N. Cao, J. Zhang et al., "High prevalence of sexually transmitted diseases among men who have sex with men in Jiangsu Province, China," Sexually Transmitted Diseases, vol. 33, no. 2, pp. 118-123, 2006.

[8] E. P. Chow, D. P. Wilson, and L. Zhang, "HIV and syphilis coinfection increasing among men who have sex with men in China: a systematic review and Meta-Analysis," PLoS ONE, vol. 6, no. 8, Article ID e22768, 2011.

[9] L. Gao, L. Zhang, and Q. Jin, "Meta-analysis: prevalence of HIV infection and syphilis among MSM in China," Sexually Transmitted Infections, vol. 85, no. 5, pp. 354-358, 2009.

[10] H. Bai, X. Huan, W. Tang et al., "A survey of HIV infection and related high-risk factors among men who have sex with men in Suzhou, Jiangsu, China," Journal of Biomedical Research, vol. 25, no. 1, pp. 17-24, 2011.

[11] Y. G. Bao, Y. H. Zhang, J. K. Zhao, J. Sun, and H. Tan, "HIV infection and KAP status among men who have sex with men in 14 Chinese cities," Chinese Journal of Preventive Medicine, vol. 43, no. 11, pp. 981-983, 2009.

[12] H. Chen, W. Luo, Y. Li et al., "Prevalence of HIV and syphilis infection in 831 MSM," Dermatology and Venereology, vol. 33, no. 4, pp. 236-237, 2011.

[13] J. Chen, Y. Wang, Y. Li et al., "Survey on HIV/syphilis infection and characteristic of MSM," Chinese Journal of Public Health, vol. 27, no. 12, p. 1604, 2011.

[14] K. Chen, X. Zhao, L. Chen et al., "Analysis on prevalence of HIV and syphilis and its risk behavior characteristics among men who have sex with men in Yongchuan district of Chongqing," Chongqing Medicine, vol. 41, no. 17, pp. 1730-1733, 2012.

[15] W. Chen, Y. Zhou, W. Jiang et al., "Monitoring of HIV/AIDS among MSM in Guilin City, Guangxi in 2010," China Tropical Medicine, vol. 12, pp. 58-60, 2012.

[16] X. Chen, J. Zhang, X. P. Huan et al., "A analysis of the high risk behaviors, HIV Infection and related factors among men who have sex with men in Yangzhou, Jiangsu Province," ACTA Universitatis Medical Nanjing (Natural Science), vol. 32, pp. 479486, 2012.
[17] E. P. Chow, L. Chen, J. Jing et al., "HIV disease burden and related risk behaviours among men who have sex with men in Yuxi Prefecture, Yunnan Province, China: 2010-2011," Aids and Behavior, vol. 17, no. 7, pp. 2387-2394, 2012.

[18] L. Dai, Y. Jiang, C. Gong et al., "The characteristic of behavior and HIV prevalence among 1315 men who have sex with men in Guangzhou," Chinese Journal of AIDS \& STD, vol. 17, no. 1, pp. 35-37, 2011.

[19] X. Ding, L. Feng, Y. Chen et al., "Study on the prevalence and related factors of HIV infection in MSM in a rural country in Chongqing," Chinese Journal of Preventive Medicine, vol. 44, no. 3, pp. 273-275, 2010.

[20] X. Ding, L. Feng, J. Xu et al., "Study on the prevalence of HIV, syphilis, HCV and HSV-II and its associated factors among 743 men who have sex with men in Chongqing," Chinese Journal Of Disease Control \& Prevention, vol. 14, no. 3, pp. 227-231, 2012.

[21] L. Feng, X. Ding, R. Lu et al., "High HIV prevalence detected in 2006 and 2007 among men who have sex with men in China's largest municipality: an alarming epidemic in Chongqing, China," Journal of Acquired Immune Deficiency Syndromes, vol. 52, no. 1, pp. 79-85, 2009.

[22] L. Feng, X. Ding, J. Xu et al., "Study on HIV, syphilis and $\mathrm{HCV}$ prevalence and its associated factors among internet MSM comparison to non-internet MSM in Chongqing," Journal of Tropical Medicine, vol. 10, no. 1, pp. 78-82, 2010.

[23] Y. Gao, Y. Liu, S. Li et al., "Prevalence and predictors of HIV, syphilis and herpes simplex type 2 virus (HSV-2) infections among the men who have sex with men (MSM) in Beijing," Chinese Journal of Public Health, vol. 28, no. 4, pp. 451-453, 2012.

[24] C. L. Gong and Q. H. Zhang, "Results of AIDS monitoring of 252 MSM in Quanzhou city," China Tropical Medicine, vol. 10, no. 12, pp. 1496-1497, 2010.

[25] H. Guo, D. Feng, L. Yi et al., "Infection status of HIV, syphilis, HCV among MSM and their behavioral charactersitic in Zunyi city," Occupational Health, vol. 28, no. 4, pp. 440-441, 2012.

[26] H. Guo, J. Wei, H. Yang, X. Huan, S. K. Tsui, and C. Zhang, "Rapidly increasing prevalence of HIV and syphilis and HIV1 subtype characterization among men who have sex with men in Jiangsu, China," Sexually Transmitted Diseases, vol. 36, no. 2, pp. 120-125, 2009.

[27] Y. Guo, X. K. Zhu, J. H. Xia et al., "Study on HIV/syphilis infections among men who have sex with men and their behavioral feature," Chinese Journal of AIDS \& STD, vol. 15, no. 1, pp. 50-71, 2009.

[28] H. Han, L. Mei, T. Han et al., "Survey on HIV/AIDS knowledge, high-risk behaviors and HIV infection among men who have sex with men in Taiyuan City," Preventive Medicine Tribune, vol. 18, no. 7, pp. 497-501, 2012.

[29] Q. He, Y. Wang, and P. Lin, "High prevalence of risk behaviour concurrent with links to other high-risk populations: a potentially explosive HIV epidemic among men who have sex with men in Guangzhou, China," Sexually Transmitted Infections, vol. 85, no. 5, pp. 383-390, 2009.

[30] S. He and H. Zhang, "Survey on characteristic and infection of HIV/syphilis in Geemu city, Qinghai province," Journal of Qinghai Medical College, vol. 42, no. 4, pp. 87-88, 2012.

[31] X. Huan, X. Chen, H. Yan et al., "Analysis of the high risk behaviors, HIV infection and related factors among men who have sex with Men in Suzhou, Jiangsu," Chinese Journal of Health Statistics, vol. 29, no. 2, pp. 202-205, 2012. 
[32] H. Y. Huang, X. P. Zhang, J. Li et al., "Studies on the HIV, syphilis and hepatitis C Infection and sexual behavior characteristic among men who have sex with men in Hefei," Modern Preventive Medicine, vol. 38, pp. 1933-1938, 2011.

[33] C. Li, Y. Jia, X. Ding, J. Liu, and Y. Xiao, "HIV infections and heterosexual behaviors among men who have sex with men in Chongqing municipality, China," Chinese Journal of Epidemiology, vol. 30, no. 9, pp. 882-886, 2009.

[34] C. M. Li, Y. Xiao, J. Liu, X. Ding, and Y. Jia, "HIV and syphilis infections among men who have sex with men in Chongqing municipality, China," Chinese Journal of Epidemiology, vol. 30, no. 2, pp. 126-130, 2009.

[35] Z. M. Liang, S. H. Chen, and Y. H. Gong, "Study on epidemiologicai situation and control strategies of HIV/AIDS among men who have sex with men in Foshan from 2008 to 2010," Journal of Medical Pest Control, vol. 27, pp. 419-421, 2011.

[36] M. Liao, D. Kang, B. Jiang et al., "Bisexual behavior and infection with HIV and syphilis among men who have sex with men along the east coast of China," Aids Patient Care and STDs, vol. 25, no. 11, pp. 683-691, 2011.

[37] L. Liu and M. Zhang, "Syphilis prevalence and its associated factors among men who have sex with men in Nanjing," ACTA Universitatis Medicinalis Nanjing (Natural Science), vol. 32, no. 7, pp. 1019-1023, 2012.

[38] P. Liu, Z. Shi, W. Shi et al., "Epidemiological study on the status of HIV/STD among MSM in Wuhan City," Chinese Journal of Disease Control \& Prevention, vol. 14, no. 9, pp. 917-919, 2010.

[39] Y. Y. Liu, B. Tian, and W. Y. Song, "Study on HIV, HCV and syphilis infection in men who have sex with men and their demographic characteristic," Practical Preventive Medicine, vol. 17, no. 4, pp. 788-790, 2012.

[40] L. Lu, D. Xu, H. H. Qiu et al., "Investigation on STDs/AIDS infection among MSM in Nanchang," Journal of Public Health and Preventive Medicine, vol. 22, pp. 45-46, 2011.

[41] H. Luo, J. Mei, L. Song et al., "A comprehensive surveillance on HIV among 1237 men who have sex with men in thirteen cities of Yunnan," Chinese Journal of Epidemiology, vol. 33, no. 7, pp. 706-709, 2012.

[42] X. Meng, Z. Xie, X. Zeng et al., "Investigation on AIDS and STD affection in MSM of Changde," Journal of Tropical Medicine, vol. 10, no. 7, pp. 884-885, 2010.

[43] C. Mou, Q. Wang, Y. Zhong et al., "Correlation between HIV antibody and sexual behaviors of men who have sex with men in Guangzhou in 2010," Journal of Southern Medical University, vol. 32, no. 1, pp. 113-115, 2012.

[44] L. Ouyang, L. Feng, X. Ding et al., "A respondent-driven sampling survey on HIV and risk factors among men who have sex with men in Chongqing," Chinese Journal of Epidemiology, vol. 30, no. 10, pp. 1001-1004, 2009.

[45] P. Pan, Y. Cai, F. Hong et al., "Investigation on high risk behavior and HIV/syphilis infection among 675 men having sex with men (MSM) in Shenzhen City," Journal of Public Health and Preventive Medicine, vol. 23, no. 3, pp. 21-23, 2012.

[46] Y. Ruan, F. Luo, Y. Jia et al., "Risk factors for syphilis and prevalence of HIV, hepatitis B and C among men who have sex with men in Beijing, China: implications for HIV prevention," Aids and Behavior, vol. 13, no. 4, pp. 663-670, 2009.

[47] S. Fan, H. Lu, X. Ma et al., "Behavioral and serologic survey of men who have sex with Men in Beijing, China: implication for HIV intervention," Aids Patient Care and STDs, vol. 26, no. 3, pp. 148-155, 2012.
[48] D. Sun, Y. Ma, Y. Nie et al., "Study on HIV/HCV and syphilis infection among MSM in two cities," Chinese Journal of Practical Medicine, vol. 37, no. 21, pp. 10-12, 2010.

[49] M. L. Sun, Y. Kong, and J. Jiang, "Dalian city MSM about HIV, HBV, HCV and syphilis infection investigation," Journal of Disease Monitor and Control, vol. 6, no. 12, pp. 708-709, 2012.

[50] M. L. Sun, D. J. Li, J. Wang et al., "Investigation on the infection of HIV, HCV, syphilis and HBV among MSM in Dalian City in 2008," Preventive Medicine Tribune, vol. 15, pp. 1074-1076, 2009.

[51] J. Tang, Z. K. Zhang, W. Jiang et al., "Survey on AIDS-related knowledge, behavior and HIV and syphilis infection among men who have sex with men in Guilin City," Preventive Medicine Tribune, vol. 18, no. 6, pp. 431-434, 2012.

[52] M. Tang, "Study on the behaviors and related diseases in men who have sex with men in Dazhou," Journal of Occupational Health and Damage, vol. 27, no. 5, pp. 314-315, 2012.

[53] F. Wang, X. Chen, Y. Xiao et al., "Analysis of the results of HIV/AIDS surveillance among men who have sex with men in Anhui Province in 2009-2010," Chinese Journal Of Disease Control \& Prevention, vol. 15, no. 8, pp. 685-688, 2011.

[54] K. L. Wang, H. M. Yan, D. H. Zhao et al., "Infection status of HIV, syphilis, and HCV and its influence factors in MSM in four cities of Heilongjiang Province," Chinese Journal of Preventive Medicine, vol. 10, no. 10, pp. 906-909, 2009.

[55] L. Wang, W. Song, and X. L. Wang, “. Survey on the knowledge, high risk behavior and HIV/syphilis infection rate among men who have sex with men of site and online types in Shenyang," Chinese Journal Of Disease Control \& Prevention, vol. 14, no. 12, pp. 1193-1196, 2010.

[56] W. Wang, L. Xue, Y. Chen et al., "Syphilis/HIV infection and KAP status among MSM in Kunshan City," Preventive Medicine Tribune, vol. 17, no. 5, pp. 395-398, 2011.

[57] X. Wang, Y. Ma, Y. Yang et al., "Study of the prevalence of HIV, syphilis and HCV in MSM in Urumqi," Journal of Dermatology and Venereology, vol. 33, no. 2, pp. 104-105, 2011.

[58] Y. Wang, J. Xu, J. L. Zhang et al., "Analysis of HIV/syphilis infection among MSM seeking sex partners in different venues and related behavior features," Chinese Journal of AIDS \& STD, vol. 18, pp. 180-183, 2012.

[59] Y. Wang, H. Yang, S. Li et al., "Investigation of acquired immunodeficiency syndrome correlated with knowledge, attitude, high risk behaviors and HIV/syphilis infection in MSM population in Shijiazhuang in 2008," Modern Preventive Medicine, vol. 38, no. 19, pp. 3958-3960, 2011.

[60] Y. Wang, H. Yang, X. Liu et al., "Investigation of acquired immunodeficiency syndrome correlated with knowledge, attitude, high risk behaviors and HIV infection in MSM population in Shijiazhuang," Clinical Focus, vol. 25, no. 12, pp. 1092-1094, 2010.

[61] Y. Y. Wang, J. Y. Chen, Y. Li et al., "Investigation on AIDS prevalence among men who have sex with men in Lanzhou city," Chinese Journal of Natural Medicines, vol. 12, pp. 327-329, 2010.

[62] Z. Wang, Z. J, L. Sun, and X. Ma, "Survey on AIDS/STD risk behaviors and prevalence among men who have sex with men in Guangling, Yangzhou," Jiangsu Journal of Preventive Medicine, vol. 21, no. 2, pp. 4-7, 2010.

[63] A. W. Wei, J. L. Zhang, and Z. L. Ma, "Analysis on AIDS, syphilis and HCV infection results among MSM people," Journal of Medical Pest Control, vol. 27, no. 8, pp. 727-732, 2011.

[64] X. D. Shi, S. Z. Liu, J. Zhao et al., "Comparisons of sexual behavor and infection of HIV and syphilis among men who 
have sex with men in Shenzhen, Guangzhou," South China Journal of Preventive Medicine, vol. 36, no. 4, pp. 22-25, 2010.

[65] F. Wen, F. Zhong, W. B. Chen et al., "HIV and current syphilis prevalence and related factors among men who have sex with men in Guangzhou," South China Journal of Preventive Medicine, vol. 36, no. 2, pp. 18-23, 2010.

[66] Y. Xiao, X. Ding, C. Li, J. Liu, J. Sun, and Y. Jia, "Prevalence and correlates of hiv and syphilis infections among men who have sex with men in chongqing municipality, China," Sexually Transmitted Diseases, vol. 36, no. 10, pp. 647-656, 2009.

[67] Y. Xiao, J. Sun, C. Li et al., "Prevalence and correlates of HIV and syphilis infections among men who have sex with men in seven Provinces in China with historically low HIV prevalence," Journal of Acquired Immune Deficiency Syndromes, vol. 53, supplement 1, pp. S66-S73, 2010.

[68] J. Xu, D. Han, Z. Liu et al., "The prevalence of HIV infection and the risk factors among MSM in 4 cities, China," Chinese Journal of Preventive Medicine, vol. 44, no. 11, pp. 975-980, 2010.

[69] J. J. Xu, K. H. Reilly, C. Lu et al., "A cross-sectional study of HIV and syphilis infections among male students who have sex with men (MSM) in northeast China: implications for implementing HIV screening and intervention programs," BMC Public Health, vol. 11, p. 287, 2011.

[70] Y. Xu, X. Zhang, Z. Zhu et al., "Analyses of the prevalence of HIV infection in MSM in Taizhou city," Jiangsu Journal of Preventive Medicine, vol. 23, no. 5, pp. 50-51, 2012.

[71] G. Yang, H. Wang, and J. C. Shi, "Survey of HIV/TP infection of gay in Dali prefecture," Chinese Journal of Health Laboratory Technology, vol. 21, no. 4, pp. 995-996, 2011.

[72] L. G. Yang, X. P. Song, X. P. Ding et al., "Study on AIDS knowledge, behavior and HIV infection among MSM in Fuyang of Anhui Province," Anhui Journal of Preventive Medicine, vol. 18, no. 1, pp. 22-27, 2012.

[73] F. Zhang, X. Zhao, X. Cao et al., "Sero-prevalence and correlates of HIV infection among men who have sex with men in Suzhou," Chinese Journal Of Disease Control \& Prevention, vol. 15, no. 12, pp. 1031-1034, 2011.

[74] L. Zhang, X. Ding, R. Lu et al., "Predictors of HIV and syphilis among men who have sex with men in a Chinese metropolitan city: comparison of risks among students and non-students," PLoS ONE, vol. 7, no. 5, Article ID e37211, 2012.

[75] L. Zhang, D. Zhang, B. Yu et al., "Prevalence of HIV infection and associated risk factors among men who have sex with men (MSM) in Harbin, PR China," PloS ONE, vol. 8, no. 3, Article ID e58440, 2013.

[76] M. Zhang, X. Wang, and Y. Yang, "Prevalence of HIV, anti$\mathrm{HCV}$, syphilis infection and AIDS knowledge among men who have sex with men (MSM) in Urumqi," Chinese Journal of Public Health, vol. 25, no. 9, pp. 1075-1076, 2009.

[77] Q. Zhang, P. Deng, Y. Geng et al., "Study on HIV/syphilis infections among men who have sex with men and their behavioral feature," China Tropical Medicine, vol. 12, no. 2, pp. 219-220, 2012.

[78] X. Zhang, J. Yu, M. Li et al., "Prevalence and related risk behaviors of HIV, syphilis, and anal HPV infection among men who have sex with men from Beijing, China," Aids and Behavior, vol. 17, no. 3, pp. 1129-1136, 2013.

[79] Y. Zhang, P. Chen, R. Lu et al., "Prevalence of HIV among men who have sex with men in Chongqing, China, 2006-2009: cross-sectional biological and behavioural surveys," Sexually Transmitted Infections, vol. 88, no. 6, pp. 444-450, 2012.
[80] Z. Zhang, N. Xu, C. Zhao et al., "Survey on the prevalence of HIV, HCV and syphilis infection from different population in Xining," Journal of Medical Pest Control, vol. 27, no. 11, pp. 10171018, 2011.

[81] J. D. Zheng, Z. Y. Wu, K. E. Poundstone, L. Pang, and K. Rou, "HIV, syphilis infection, and risky sexual behaviors among male university students who have sex with men in Beijing, China: a cross-sectional study," Aids Education and Prevention, vol. 24, no. 1, pp. 78-88, 2012.

[82] F. Zhong, P. Lin, H. Xu et al., "Possible increase in HIV and syphilis prevalence among men who have sex with men in Guangzhou, China: results from a respondent-driven sampling survey," Aids and Behavior, vol. 15, no. 5, pp. 1058-1066, 2011.

[83] C. Zhou, X. B. Ding, L. G. Feng et al., "Study on the prevalence and associated factors of HIV and syphilis among 1166 men who have sex with men," Modern Preventive Medicine, vol. 38, no. 5, pp. 815-820, 2011.

[84] C. Zhou, H. F. Raymond, X. B. Ding et al., "Anal sex role, circumcision status, and HIV infection among men who have sex with men in Chongqing, China," Archives of Sexual Behavior, vol. 42, no. 7, pp. 1275-1283, 2013.

[85] J. Zhou, C. Hao, X. Huan et al., "HIV and syphilis infections among men who have sex with men," Chinese Journal of Public Health, vol. 28, no. 8, pp. 1031-1035, 2012.

[86] Y. Zhou, J. Gao, K. Gu et al., "Testing of HIV and syphilis and investigation of risk factors among 416 MSM," Chinese Primary Health Care, vol. 26, no. 11, pp. 72-74, 2012.

[87] Z. Zhou, S. M. Li, Y. Liu et al., "Study on the relationship between behavioral factors, psychological status and HIV infection among men who have sex with men in Beijing," Chinese Journal of Epidemiology, vol. 31, no. 3, pp. 273-276, 2010.

[88] C. Zhu and H. Lu, "Surveillance of HIV/syphilis infection on 259 MSM," Jiangsu Journal of Preventive Medicine, vol. 22, no. 6, p. 34, 2011.

[89] H. Zou, Z. Wu, J. Yu et al., "Sexual risk behaviors and HIV infection among men who have sex with men who use the internet in Beijing and Urumqi, China," Journal of Acquired Immune Deficiency Syndromes, vol. 53, supplement 1, pp. S81S87, 2010.

[90] Y. Y. Liu, "Study on HIV, HCV and syphilis infection in men who have sex with men and their demographic characteristic," Changsha, 2012.

[91] L. Qu, "Prvalence of HIV infection and its assoiated factors among 805 MSM in Inner Mongolia," 2011.

[92] H. Han, "Survey on HIV/AIDS knowledge, high-risk behaviors and HIV infection among men who have sex with men in Taiyuan City," Taiyuan, 2012.

[93] "Survey on AIDS-related knowledge, behavior and HIV and syphilis infection among men who have sex with me.9n in Guilin City Tang J," Guilin, 2012.

[94] H. Bai, X. Huan, W. Tang et al., "A survey of HIV infection and related high-risk factors among men who have sex with men in Suzhou, Jiangsu, China," Journal of Biomedical Research, vol. 25, no. 1, pp. 17-24, 2011.

[95] C. Zhou, "Study on the prevalence and associated factors of HIV and syphilis among 1166 men who have sex with men," Chongqing, 2011.

[96] M. Liao, D. Kang, B. Jiang et al., "Bisexual behavior and infection with HIV and syphilis among men who have sex with men along the east coast of China," AIDS Patient Care and STDs, vol. 25, no. 11, pp. 683-691, 2011. 
[97] L. Feng, X. Ding, R. Lu et al., "High HIV prevalence detected in 2006 and 2007 among men who have sex with men in China's largest municipality: an alarming epidemic in Chongqing, China," Journal of Acquired Immune Deficiency Syndromes, vol. 52, no. 1, pp. 79-85, 2009.

[98] "HIV disease burden and related risk behaviours among men who have sex with men in Yuxi Prefecture, Yunnan Province, China: 2010-2011 Chow EP," Yuxi, 2011.

[99] F. Zhong, P. Lin, H. Xu et al., "Possible increase in HIV and syphilis prevalence among men who have sex with men in Guangzhou, China: results from a respondent-driven sampling survey," AIDS and Behavior, vol. 15, no. 5, pp. 1058-1066, 2011.

[100] X. Zhang, J. Yu, M. Li et al., "Prevalence and Related Risk Behaviors of HIV, Syphilis, and Anal HPV Infection Among Men who have Sex with Men from Beijing, China," AIDS and Behavior, pp. 1-8, 2011.

[101] Y. Zhang, P. Chen, R. Lu et al., "Prevalence of HIV among men who have sex with men in Chongqing, China, 2006-2009: cross-sectional biological and behavioural surveys," Sexually Transmitted Infections, vol. 88, no. 6, pp. 444-450, 2012.

[102] H. Guo, J. Wei, H. Yang, X. Huan, S. K. Tsui, and C. Zhang, "Rapidly increasing prevalence of HIV and syphilis and HIV1 subtype characterization among men who have sex with men in Jiangsu, China," Sexually Transmitted Diseases, vol. 36, no. 2, pp. 120-125, 2009.

[103] Y. Ruan, F. Luo, Y. Jia et al., "Risk factors for syphilis and prevalence of HIV, hepatitis B and C among men who have sex with men in Beijing, China: implications for HIV prevention," AIDS and Behavior, vol. 13, no. 4, pp. 663-670, 2009.

[104] H. Zou, Z. Wu, J. Yu et al., "Sexual risk behaviors and HIV infection among men who have sex with men who use the internet in Beijing and Urumqi, China," Journal of Acquired Immune Deficiency Syndromes, vol. 53, no. 1, pp. S81-S87, 2010.

[105] F. H. Wang, "Analysis of the results of HIV/AIDS surveillance among men who have sex with men in Anhui Province in 20092010," 2011.

[106] Y. J. Gao, "Prevalence and predictors of HIV, syphilis and herpes simplex type 2 virus (HSV-2) infections among the men who have sex with men (MSM) in Beijing," Beijing, 2012.

[107] Z. H. Zhou, S. M. Li, and Y. J. Liu, "Study on the relationship between behavioral factors, psychological status and HIV infection among men who have sex with men in Beijing," Zhonghua Liu Xing Bing Xue Za Zhi, vol. 31, no. 3, pp. 273-276, 2010.

[108] Y. Q. Zhou, "Testing of HIV and syphilis and investigation of risk factors among 416 MSM," Shanghai, 2012.

[109] L. P. Dai, "The characteristic of behavior and HIV prevalence among 1315 men who have sex with men in Guangzhou," Guangzhou, 2011.

[110] C. H. Mou, "Correlation between HIV antibody and sexual behaviors of men who have sex with men in Guangzhou in 2010," Guangzhou, 2012.

[111] W. Wang, "Syphilis/HIV infection and KAP status among MSM in Kunshan City," Kunshan, 2011.

[112] S. Y. Sun, "Study on HIV/HCV and syphilis infection among MSM in two cities," 2010.

[113] J. J. Chen, "Survey on HIV/syphilis infection and characteristic of MSM," Lanzhou, 2011.

[114] F.-C. Hong, H. Zhou, Y.-M. Cai et al., "Prevalence of syphilis and HIV infections among men who have sex with men from different settings in Shenzhen, China: implications for HIV/STD surveillance," Sexually Transmitted Infections, vol. 85, no. 1, pp. 42-44, 2009.
[115] S. H. He, "Survey on characteristic and infection of HIV/ syphilis in Geemu city, Qinghai province," Geermu, 2012.

[116] X. D. Shi, "Comparisons of sexual behavor and infection of HIV and syphilis among men who have sex with men in Shenzhen, Guangzhou," Shenzhen, 2010.

[117] Y. M. Cai, "Distribution characteristics and influencing factors of syphilis among men who have sex with men in Shenzhen," Shenzhen, 2012.

[118] Y. Y. Wang, "Investigation of Acquired Immunodeficiency Syndrome correlated with knowledge, attitude, high risk behaviors and HIV/syphilis infection in MSM population in Shijiazhuang in 2008," Shijiazhuang, 2011.

[119] H. Bai, X. Huan, W. Tang et al., "A survey of HIV infection and related high-risk factors among men who have sex with men in Suzhou, Jiangsu, China," Journal of Biomedical Research, vol. 25, no. 1, pp. 17-24, 2011.

[120] A. S. Wade, C. T. Kane, P. A. Niang Diallo et al., "HIV infection and sexually transmitted infections among men who have sex with men in Senegal," Aids, vol. 19, no. 18, pp. 2133-2140, 2005.

[121] L. R. Kerr, R. S. Mota, C. Kendall et al., "HIV among MSM in a large middle-income country," Aids, vol. 27, pp. 427-435, 2013.

[122] F. van Griensven, "Men who have sex with men and their HIV epidemics in Africa," Aids, vol. 21, no. 10, pp. 1361-1362, 2007.

[123] S. Baral, F. Sifakis, F. Cleghorn, and C. Beyrer, "Elevated risk for HIV infection among men who have sex with men in lowand middle-income countries 2000-2006: a systematic review," PLoS Medicine, vol. 4, no. 12, Article ID e399, pp. 1901-1911, 2007.

[124] K. Yun, J. J. Xu, K. H. Reilly et al., "Prevalence of bisexual behaviour among bridge population of men who have sex with men in China: a meta-analysis of observational studies," Sexually Transmitted Infections, vol. 87, no. 7, pp. 563-570, 2011. 


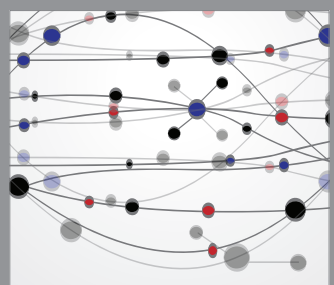

The Scientific World Journal
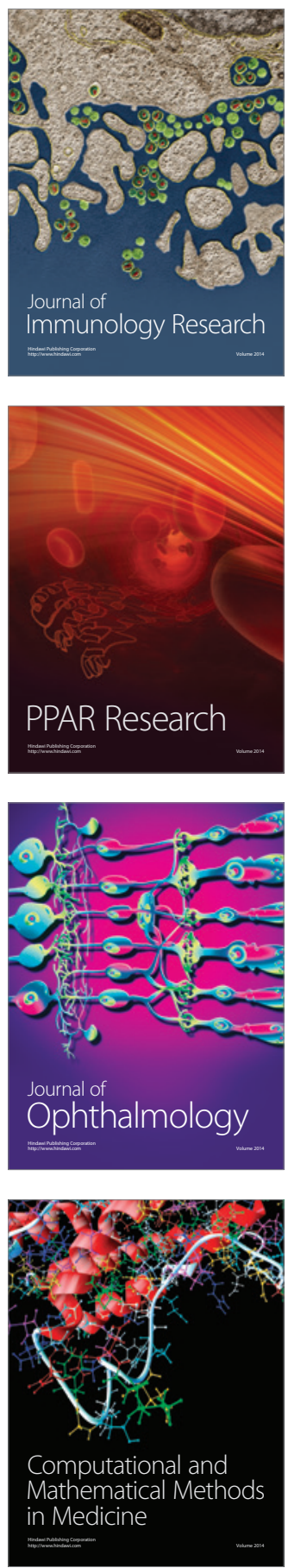

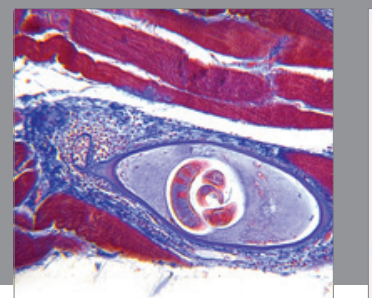

Gastroenterology

Research and Practice
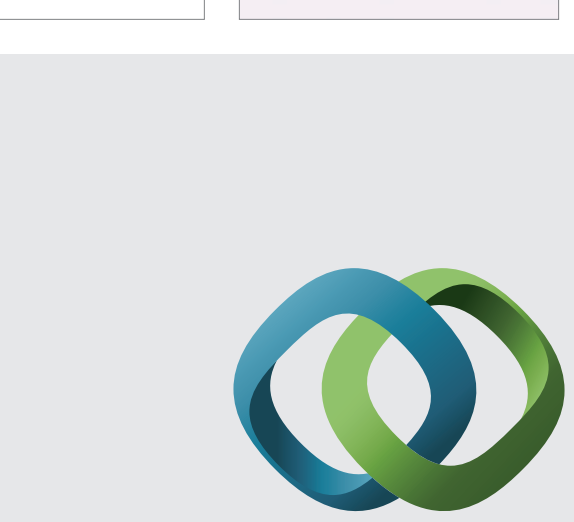

\section{Hindawi}

Submit your manuscripts at

http://www.hindawi.com
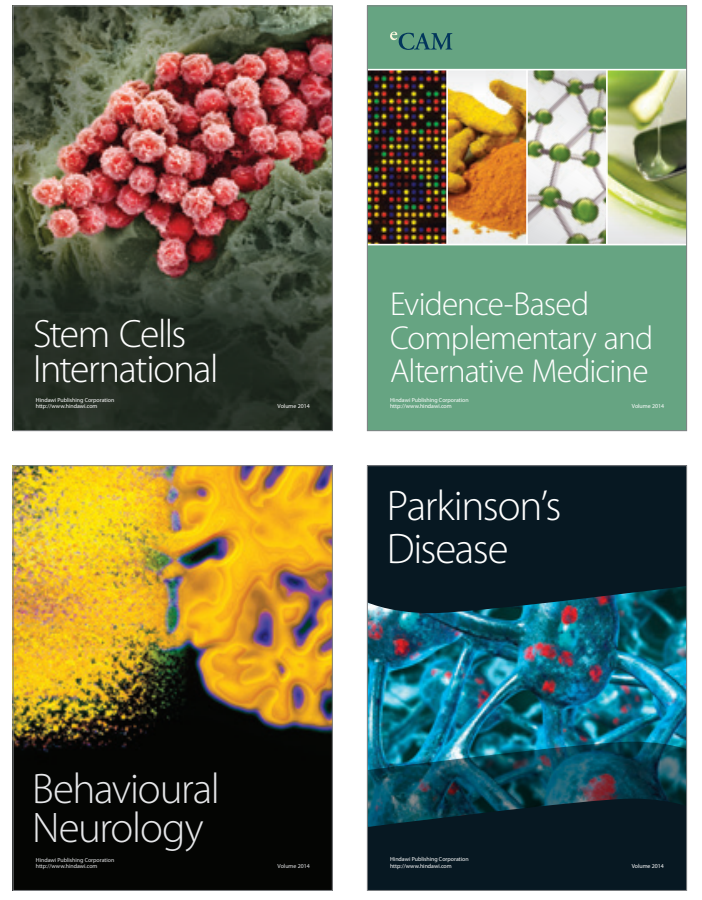
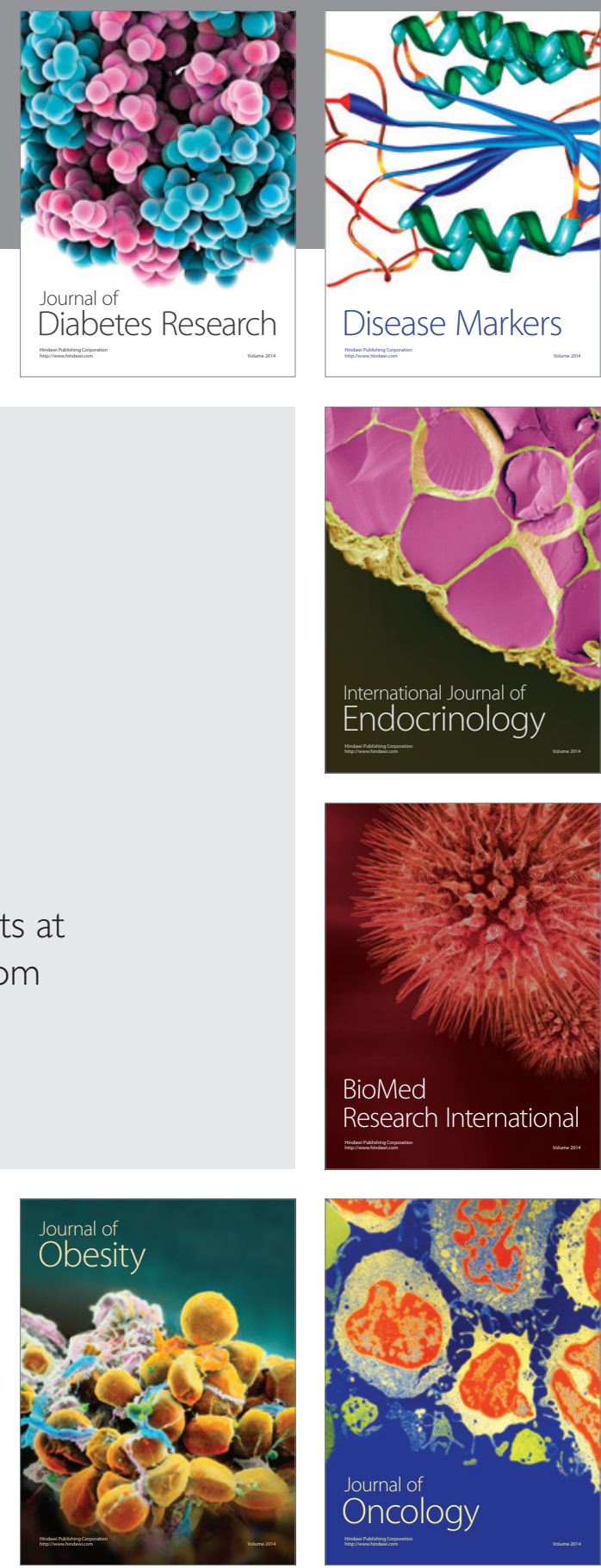

Disease Markers
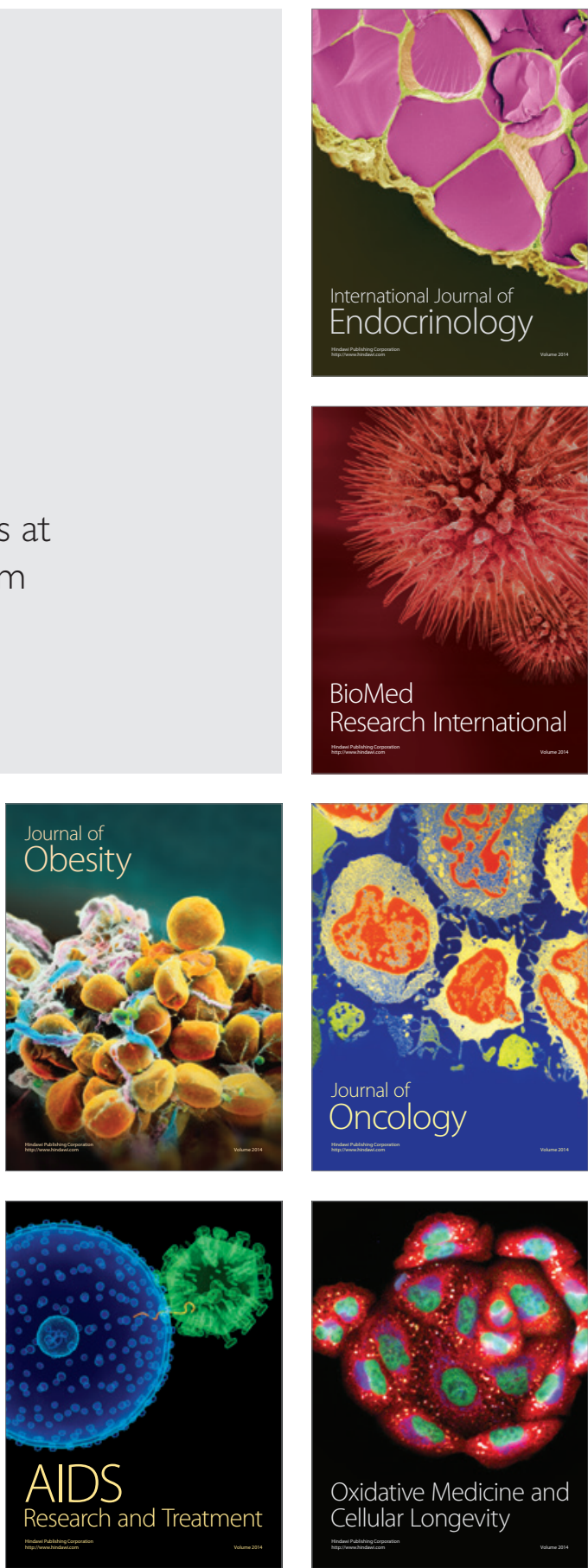